\title{
Chronic Painless Parotid Swelling
}

\author{
Ju Yeon Kim, M.D. ${ }^{1}$, Jin Kyun Park, M.D., Ph.D. ${ }^{2}$ \\ ${ }^{1}$ Department of Internal Medicine, ${ }^{2}$ Division of Rheumatology, Department of Internal Medicine, Seoul National University Hospital, Seoul, \\ Korea
}

\section{A 29-year-old woman with primary Sjögren's syndrome} (SS) presented with chronic painless swelling of both parotid glands (Figure 1A). Four years previously, SS was diagnosed based on sicca symptoms, positive anti-SSA/Ro antibody, and lymphocytic infiltrates and sclerotic changes on parotid gland biopsy. Two years ago, she was diagnosed with extranodal marginal zone B-cell lympho- ma (EMZBCL) of the left conjunctiva, which was treated successfully with radiation therapy. She was referred to our medical center for evaluation of refractory parotiditis. She denied Raynaud's phenomenon.

At presentation, both parotid glands were enlarged without tenderness, heat, or redness (Figure 1A, arrowheads). High-sensitivity C-reactive protein levels and the
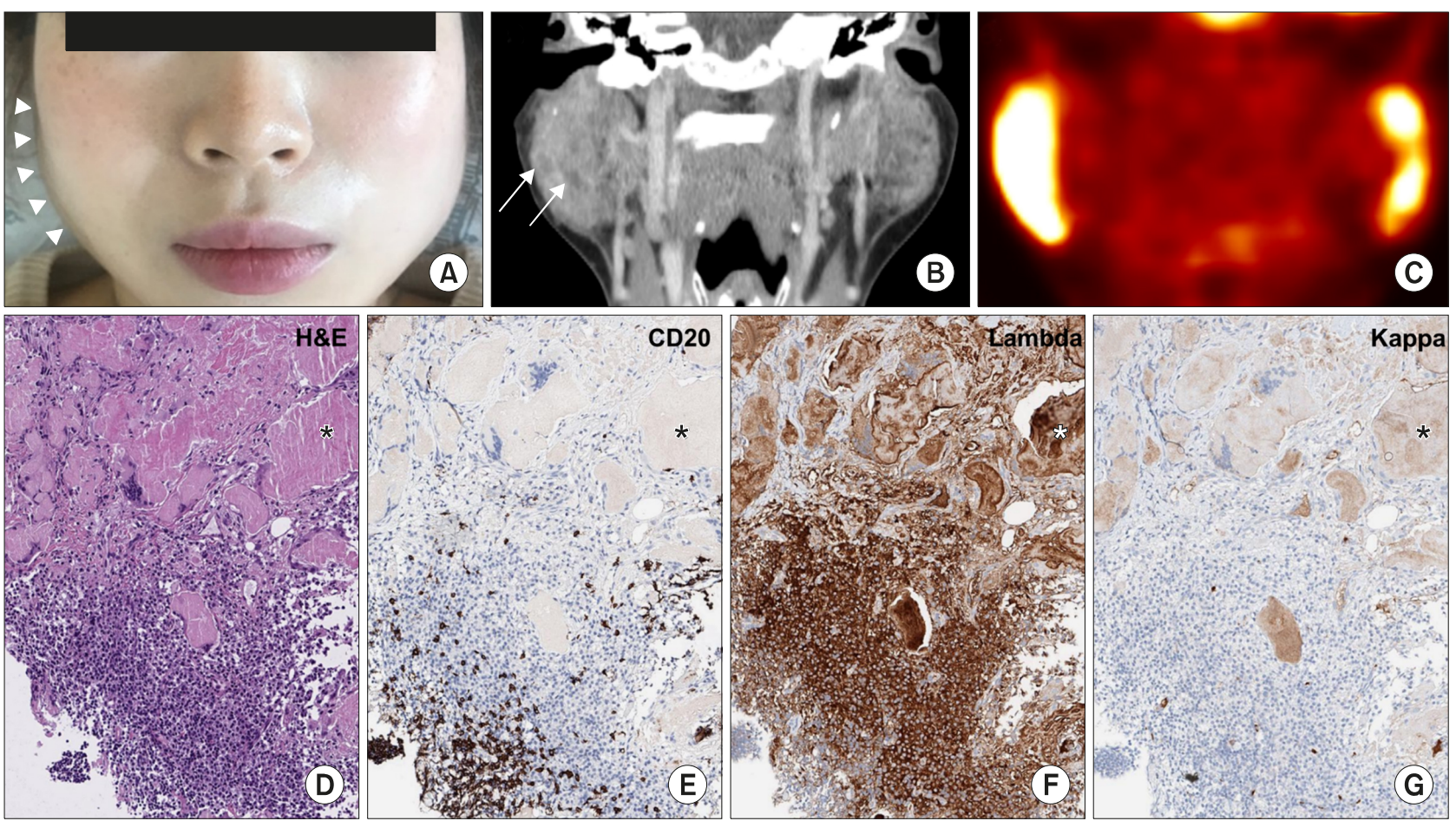

Figure 1. (A) Bilateral parotid glands swelling (arrowheads). (B) Enlarged parotid glands with multiple cysts (arrows) and solid nodules on computed tomography. (C) Strong uptake in the bilateral parotid glands on positron emission tomography. (D) B-cell lymphoma with amorphous amyloid aggregates (asterisk) on parotid gland biopsy (H\&E, $\times 150)$. (E) Infiltration of CD20 positive cells $(\times 150)$. $(F, G)$ Lambda chain restriction on immunohistochemical analysis for lambda $(F)$ and kappa $(G)$ light chains $(\times 150)$.

Received : September 18, 2020, Revised : October 30, 2020, Accepted : November 2, 2020

Corresponding to : Jin Kyun Park (DiDttp://orcid.org/0000-0003-2167-9393

Division of Rheumatology, Department of Internal Medicine, Seoul National University Hospital, 101 Daehak-ro, Jongno-gu, Seoul 03080, Korea. E-mail : jinkyunpark@gmail.com

Copyright (c) 2021 by The Korean College of Rheumatology.

This is an Open Access article, which permits unrestricted non-commerical use, distribution, and reproduction in any medium, provided the original work is properly cited. 
erythrocyte sedimentation rate were $0.03 \mathrm{mg} / \mathrm{dL}$ (normal $<0.5 \mathrm{mg} / \mathrm{dL}$ ) and $33 \mathrm{~mm} / \mathrm{hr}$ (normal $<20 \mathrm{~mm} / \mathrm{hr}$ ), respectively. Rheumatoid factor was 93 (normal $<15$ $\mathrm{U} / \mathrm{mL}$ ). The antinuclear antibody titer was 1:320 with positive anti-SSA/Ro and anti-SSB/La antibodies. Serum protein electrophoresis revealed mild hypergammaglobulinemia but no M-spike was detected. Serum IgG subclass 4 was $32 \mathrm{mg} / \mathrm{dL}$ (normal $<86.4 \mathrm{mg} / \mathrm{dL}$ ) and Schirmer's test was $0 / 0 \mathrm{~mm}$ (left/right eye). A salivary gland scan showed a mild reduction in excretory function. Computed tomography (CT) of the salivary gland revealed enlarged parotid glands with multiple cystic (arrows) and solid nodules (Figure 1B). Positron emission tomography revealed increased uptake by the bilateral parotid glands (Figure 1C).

An ultrasound-guided gun biopsy of the right parotid gland revealed non-Hodgkin's B-cell lymphoma, accompanied by homogeneous, amorphous amyloid aggregates (asterisk) on hematoxylin and eosin staining (Figure 1D). Immunohistochemistry revealed infiltration by lympho-plasma cells (Figure 1E), which showed restricted expression of lambda chains (Figure 1F, G). CT of the chest and abdomen was normal. Bone marrow biopsy showed no malignant cells. A recurrent EMZBCL with amyloidosis of the parotid glands was diagnosed [1-3]. Chemotherapy with rituximab, cyclophosphamide, vincristine, and prednisolone was started. Chronic painless swelling of the salivary glands in SS patients warrants a further investigation to rule out concurrent lymphoma and/or amyloidosis.

\section{CONFLICT OF INTEREST}

No potential conflict of interest relevant to this article was reported.

\section{AUTHOR CONTRIBUTIONS}

J.K.P. conceived of the study design. J.Y.K. and J.K.P. performed data acquisition and interpretation. All authors prepared and approved the final manuscript.

\section{REFERENCES}

1. Hernandez-Molina G, Faz-Munoz D, Astudillo-Angel M, Iturralde-Chavez A, Reyes E. Coexistance of amyloidosis and primary Sjögren's syndrome: an overview. Curr Rheumatol Rev 2018;14:231-8.

2. Ikeda SI, Hineno A, Yoshinaga T, Matsuo K, Suga T, Shiina $\mathrm{T}$, et al. Sjögren syndrome-related plasma cell disorder and multifocal nodular AL amyloidosis: clinical picture and pathological findings. Amyloid 2019;26:225-33.

3. Retamozo S, Brito-Zerón P, Ramos-Casals M. Prognostic markers of lymphoma development in primary Sjögren syndrome. Lupus 2019;28:923-36. 